\title{
Research on Countermeasures for the Development of Rural E-Commerce Logistics
}

\author{
Yuan Peng ${ }^{1, *}$ \\ ${ }^{1}$ Chongqing Technology and Business University, Business Administration, Chongqing 400020, China
}

\begin{abstract}
Under the current environment, rural e-commerce logistics have become the focus of attention from all walks of life, and various e-commerce enterprises and logistics companies have entered the rural market under the county to achieve the purpose of expanding their market share. Based on the characteristics, current situation, and problems of developing rural e-commerce logistics in Huade County of Ulanqab City, Inner Mongolia Autonomous Region. The article using Schematic diagram of Milk Run optimisation model and E-Commerce Logistics Distribution Model, puting forward several countermeasures suitable for the development of rural e-commerce logistics in Huade County.
\end{abstract}

\section{Introduction}

The rural e-commerce market is continuing to heat as rural residents' spending power increases, and the internet is still gain popularity. Although rural electronic commerce logistics happen from time to time, there are still a series of inadequate infrastructure, less express business, lack of professional talents and more traditional consumption concepts, leading to a particular gap between rural and urban e-commerce logistics development.

Huang Wei ${ }^{[1]}$ analysed the symbiotic development of rural e-commerce and logistics from blockchain technology. Liu Dewu ${ }^{[2]}$ studied the impact of logistics efficiency improvement on rural e-commerce development based on the perspective of rural economic development. Zhong Yanqiong ${ }^{[3]}$ analysed the current development of rural e-commerce and studied its impact on the consumption of rural residents. Zuo Xiaofen ${ }^{[4]}$ analysed the current situation of the "last mile" of rural e-commerce logistics from the perspective of "Internet+" and put forward corresponding countermeasures. This paper takes rural e-commerce logistics in Huade County, Ulanqab City, Inner Mongolia Autonomous Region as the research object, analyzes the problems of rural e-commerce logistics in Huade County and puts forward several countermeasures suitable for the development of rural e-commerce logistics in Huade County.

\section{Huade County rural e-commerce logistics}

\subsection{Overview of the development of rural e-commerce logistics in Huade County}

According to the statistics on Huade County People's Government website, Huade County has 2534 square kilometres, 87 village committees, nine communities, 325 natural villages, and a registered population of 163,700 people. SF Holding, ZTO Express, YUNDA and other courier companies are primarily distributed in the county and slightly better-developed villages. While other villages have only a few courier outlets, some places even have only China Postal Express network points. Rural e-commerce logistics in Haidian County are scarce and lagging in development.

\subsection{Development Characteristics of rural e-commerce logistics in Huade County}

According to the 2020 Ulanqab News, the State Ministry of Commerce with 2018 listed Huade County as a comprehensive demonstration county for e-commerce into rural areas. Driven by the demonstration project, Huade County comprehensively builds a rural e-commerce service network and logistics distribution system covering the county, township (town) and village levels. 


\subsubsection{Vigorously develop the e-commerce industrial park}

In 2017, Huade County invested 14 million yuan in implementing the construction of an e-commerce industrial park. The State Ministry of Commerce listed Huade County as a comprehensive demonstration county of e-commerce into rural areas in 2018. Huade County has carried out several demonstration projects, optimized the various functional areas of the e-commerce industrial park, added a live operation centre, a public service centre for small and medium enterprises, and introduced several vital e-commerce enterprises park.

\subsubsection{Integration of resources to establish a third-party platform}

To better serve the electric business express into the countryside, Huade County in the electric business industry park set up a logistics distribution centre, Yuan Tong, China Tong, Shentong and other six express enterprises stationed. At the same time, to pass the industrial products to the countryside and agricultural products into the city "the last kilometre" of the problem, built rural electric business service station 43 , logistics service station 51, logistics distribution range to reach the administrative village service coverage rate of $82 \%$.

\section{Problems in the development of rural e-commerce logistics in Huade County}

\subsection{Infrastructure is not perfect}

Huade County has a wide geographical area and a relatively scattered population distribution, which has increased the difficulties for logistics distribution. According to the data published by the China Poverty Alleviation Inner Mongolia Channel, as of 2019, Huade County has built six new roads to villages of 45 kilometres, an increase of $9.8 \%$. Although the county's highway rural access rate reached $100 \%$, most of the villages have only a simple road between them, and there are long distances and countryside dirt roads between each collection point. Couriers often need to spend more effort and time than urban logistics to ensure that goods are delivered to consumers intact, leading many courier companies to be reluctant to take logistics orders from rural areas ${ }^{[4]}$.

Simultaneously, although rural network coverage in Huade County is growing fast, there are still areas where the internet is not widely available, which has also caused problems. The lack of real-time tracking of logistics information makes e-commerce lose its informational advantages, resulting in its inability to use advanced logistics management information systems as generally as in the cities. When goods arrive in rural areas, logistics companies and residents cannot be accurately informed of cargo information and are prone to problems such as loss and delay of goods. The additional costs and burdens imposed on e-commerce enterprises and logistics companies have also reduced the benefits that information technology can bring to consumers, significantly limiting the development of rural e-commerce logistics in Huade County.

\subsection{Consumers' limitations}

Huade County villagers do not know enough about e-commerce and are influenced by traditional shopping thoughts. Villagers in Huade County prefer to rush to markets and supermarkets and focus on whether the price of goods is low. At the same time, they tend to believe in goods that they can "see with their own eyes and touch with their own hands", which gives rural residents a sense of security.

\section{Suggestions for the development of rural e-commerce logistics in Huade County}

\subsection{Improving the construction of infrastructure mainly in the transportation network}

\subsubsection{Reasons for improving the transport network}

The development of e-commerce logistics in rural areas with underdeveloped transportation will be a "pain point" for logistics. Most of the rural villages in Huade County are on dirt roads in the countryside, and most of the villages are connected by only one main concrete road. Villagers travel mainly by foot and motorbike, which reduce the efficiency of logistics distribution. For this reason, it is imperative to improve the transport network. E-commerce companies need to consider joining forces with logistics companies and local governments to solve bad roads in rural Huade County. By building roads, traffic conditions can be improved, saving logistics and distribution costs and reducing poverty.

\subsubsection{The social benefits of improving the transport network}

This paper argues that improving the transport network in rural areas of Huade County is of great significance, effectively increasing income and reducing poverty in two ways.

\subsubsection{Reducing transport costs.}

Improving the transport network makes transport conditions more convenient. It saves a lot of transport time, making the flow of goods and labour more frequent, which reduces transport costs and lowers the prices of various commodities, which is highly beneficial to the development of rural e-commerce logistics. 


\subsubsection{Promoting economic development.}

There is no doubt that areas with developed transportation generally have better economic development. In turn, areas with developed economies have more convenient transportation, and the two are mutually reinforcing. Improving the transportation network makes the vehicle in rural areas more convenient, making it easier and faster for industrial goods to go to the countryside and agricultural products to enter the city. It can effectively drive the development of the farming and non-agricultural economies in rural areas and make the employment structure and income sources more diversified. Simultaneously, convenient transportation conditions will also improve local education and medical care, achieving the goal of reducing poverty.

\subsection{Milk Run model}

\subsubsection{Program overview}

The Milk Run model originated from the vehicle route problem proposed by Ramser et al. in 1959 which is an optimized logistics network distribution model.

Through a fixed location at a fixed time every day, a reasonable number of vehicles are arranged along the established route to deliver the customer's parcel from the logistics centre to the consumer safely and accurately or to collect the property that needs to be sent out from the customer's hand and send it to the logistics centre. Aim to achieve the lowest transportation cost, the highest distribution efficiency, and the most optimal vehicle return loading rate in this process. The Milk Run model was set up to solve insufficient express business, and often empty return trips with low loading rates in rural Huade County. There are several routes from the logistics centre, each of which forms a demand sequence. This demand sequence needs to be optimised by keeping transport costs to a minimum and transport distances to a minimum. As shown in the diagram below, 0 represents the logistics centre, and the rest of the figures represent each township logistics site or customer terminal, forming three routes: $0-1-2-3-0,0-4-5-6-0$ and $0-7-8-9-10-0$.

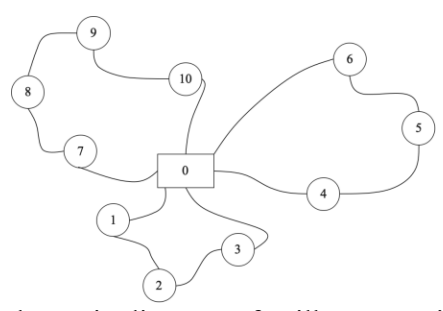

Fig. 1. Schematic diagram of Milk Run optimisation

\subsubsection{Feasibility analysis}

\subsubsection{Assembly rate analysis}

Due to the lack of demand for express business in rural areas of Huade County, about $80 \%$ of the townships have an average daily volume of fewer than 60 pieces of express delivery, resulting in a low assembly rate. The Milk Run model can effectively solve this difficulty, especially in the "small volume, multi-frequency" characteristics. The Milk Run model at multiple logistics stations can improve the vehicle's loading rate, reducing the overall operation and distribution costs.

\subsubsection{Economic analysis}

From the analysis in Table 1, Direct delivery safety is better, and the responsibility is more explicit. However, Direct delivery requires each logistics site to dispatch a different vehicle, with a high empty rate, uneconomical transportation and difficulty in ensuring timeliness, which applies to situations where the number of express shipments is high. The Milk Run solution effectively reduces the overall transportation costs, lower personnel and vehicles' occupation, and is more economical. Combined with the small number of express shipments in rural Huade County mentioned above, the Milk Run model is more suitable for constructing rural e-commerce logistics in Huade County.

\subsubsection{Possible implementation effects}

Under normal circumstances, implementing The Milk Run model in the less developed rural areas of Huade County can significantly reduce overall logistics operating costs and reduce the number of empty vehicle trips. However, there are unforeseen circumstances, such as rain and snow, which may reduce the vehicles' speed, extend the delivery time.

Table 1. Comparison of the two distribution models

\begin{tabular}{|c|c|c|c|c|}
\hline & Loading rate & Transport distance & Vehicle resources & Personnel occupancy \\
\hline Direct delivery & Low & long & High occupancy & High occupancy \\
\hline Milk Run & High & Short & Low occupancy & Low occupancy \\
\hline
\end{tabular}




\subsection{Other countermeasures and suggestions}

\subsubsection{Change the consumption concept of rural residents}

According to the data from the government work report of Huade County in Inner Mongolia 2020, the per capital disposable income of urban residents in Huade County increased by $8 \%$ year-on-year in 2019, and the disposable income of rural residents increased by $11.2 \%$ year-on-year. Residents' purchasing power is rising, and their desire and confidence in consumption are gradually rising. However, Huade County residents are more traditional in their consumer attitudes and do not know how to operate a computer, let alone the process of online shopping, and are still stuck in the "pay with one hand and deliver with the other" mode of transaction. Therefore, publicity personnel can be dispatched to promote and introduce villagers' online shopping process to experience the thrill of shopping in the information age. Besides, as brick-and-mortar shops in rural areas do not pay much attention to after-sales service, if e-commerce logistics companies can enhance after-sales service in rural areas, it will increase rural areas' satisfaction residents with online shopping and win their praise. It will stimulate rural residents' consumption demand through a rich consumption experience and promote the transformation of ruralresidents' consumption concepts to developmental and enjoyment-oriented consumption concepts ${ }^{[5]}$.

\subsubsection{Cooperation with China Post Logistics and supermarkets}

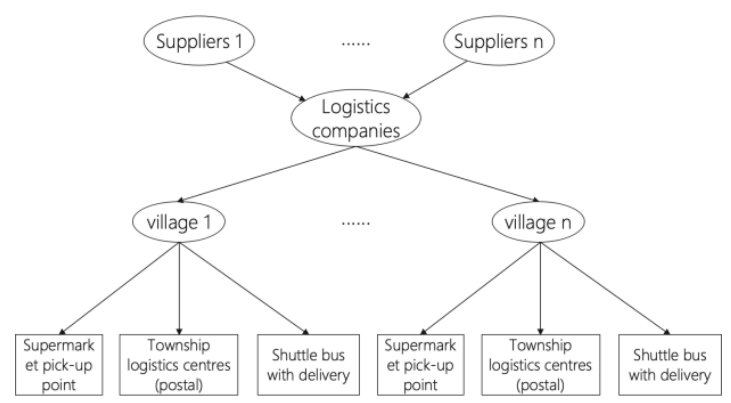

Fig. 2. Huade County Rural E-Commerce Logistics Distribution Model

China Post Logistics has a unique advantage in that its logistics network is widely distributed and involves all country regions, with a high degree of information technology. The postal service has a $100 \%$ coverage rate in all towns and villages in Huade County, with numerous outlets.

There are supermarkets in every village, and then vehicles are dispatched as transport shuttles, which are mainly used to deliver parcels with the cars. As shown in Figure 2, If the courier business and postal services, supermarkets, shuttles, and other distribution methods are combined. In the terminal for cooperation in distribution, parcels sent to the logistics companies, logistics companies through the Milk Run method to the supermarket pick-up point, shuttle bus points, postal centres, so that the parcels sent to the villagers. This will save considerable logistics costs, thus improving the efficiency of logistics distribution and opening up the last link for the sprint of the "last mile" of rural logistics. This is shown in Figure 2 below.

\section{Conclusion}

This paper analyses the development of rural e-commerce logistics in Huade County according to the characteristics of its network and road conditions, logistics services, logistics sites and speed of receipt. It is concluded that the problems of the current development of rural e-commerce logistics in Huade County are mainly inadequate infrastructure, lack of professional talents and traditional consumer concepts. These lead to the development of rural e-commerce logistics with high costs, slow timeliness and complex layout. In response to these existing problems, measures are proposed to improve the transportation network, establish a circular pick-up and delivery model, change the consumption concept of rural residents, and cooperate with local postal services and supermarkets, based on a comprehensive view of previous studies.

However, the sample size chosen in this paper is small, and the coverage is not extensive, so there are inevitably gaps in the analysis. Therefore, future research can increase the sample size and expand the survey's scope. The problems that exist can be further demonstrated so that the data analysis can be more accurate.

\section{References}

1. W. Huang, R.R. Chang, R. Chang, Business and Economic Research. J. 6, 118-121 (2019)

2. D.W. Liu, Y.G. Liu, Business Economic Research. J. 23, 117-119 (2018)

3. Y.Q. Zhong, Business and Economic Research. J. 11, 173-175 (2016.11)

4. X.F. Zuo, Modern Economic Information. J. 23, 284-285 (2018)

5. X.T. Mao, L.G. Chai, Modern Marketing. J. 11, 38-39 (2011) 